\title{
PERANCANGAN SISTEM INFORMASI PENDAFTARAN PASIEN RAWAT JALAN BERBASIS VISUAL BASIC DI RUMAH SAKIT IMELDA PEKERJA MEDAN.
}

\author{
${ }^{1 .}$ Sofyan., M.Kom; ${ }^{2 \cdot}$ Khatika Bahar Harahap \\ ${ }^{1 .}$ Dosen APIKES Imelda, Jalan Bilal Nomor 52 Medan; ${ }^{2}$ Alumni APIKES Imelda \\ E-mail: ${ }^{l .}$ SofyanAkademik@gmail.com
}

\begin{abstract}
ABSTRAK
Rekam medis elektronik merupakan catatan rekam medik pasien seumur hidup dalam format elektronik tentang kesehatan seseorang yang dituliskan oleh satu atau lebih petugas kesehatan secara terpadu dalam tiap kali pertemuan anatar petugas kesehatan dengan klien. Tujuan penelitian ini adalah untuk mengetahui bagaimana perancangan sistem informasi pendaftaran pasien rawat jalan dirumah sakit imelda pekerja indonesia serta untuk mengetahui alur dan kurangan dalam pelaksanaan rekam medisyang terkomputerisasi. Jenis penelitian ini adalah STRADIS (Structur Analysis Design and implementation of Information System) bertujuan melakukan pengembangan tools dalam perancangan sistem dengan menggunaan Data Flow Diagram(DFD).Dalam melakukan penelitian, peneliti melakukan observasi terhadap alur pendaftarara pasien dan menggambil sampel sebanyak 20 pegawaipendaftaran pasien. Berdasarkan hasil penelitian yang dilakukan di RSU Imelda Pekerja Indonesia pelaksanaan pendaftaran pasien rawat jalan masih belum bejalan dengan baik dilihat dari observasi yang dilakukan peneliti masih belum terlaksananya pemeberian nomor antrian setiap melakukan pendaftaran dan kekurangan lainya pada jaringan saat melakukan Proses penyimpanan atau pencarian. Kesimpulannya perancangan sistem informasi pendaftaran pasien rawat jalan dapat berjalan sesuai kebutuhan namun alur dan penggunaan kompueterisasi lebih diperhatikan sesuai kebutuhan rumah sakit.
\end{abstract}

Kata Kunci: Rekam Medis Elektronik, Alur Pendaftaran Pasien Rawat Jalan, Data Flow Diagram (DFD)

\section{PENDAHULUAN}

Salah satu kesehatan yang saat ini berkembang di berbagai Negara dalam mengadopsi teknologi informasi dan komunikasi (TIK) yaitu e-kesehatan (eHealth). E-kesehatan menurut WHO secara singkat adalah penggunaan TIK untuk kesehatan. Dalam arti luas,e-Kesehatan berhubungan dengan upaya meningkatkan arus informasi, melalui sarana elektronik,untuk mendukung pelayanan kesehatan dan pengolahan sistem kesehatan. Istilah e-Kesehatan harus diartikan secara histolik, tidak hanya terkait pada aspek teknis,tetapi juga menyangkut sikap dan pola fikir yang berwawasan global dengan melihat pemamfaatan TIK tidak semata-mata untuk menunjang pelayanan kesehatan dalam hubungan dengan kepentingan local ataupun nasional, namun juga dalam kaitannnya dengan kepentingan regional maupun dunia (Hatta,2014).

Seiring dengan perkembangan teknologi informasi dan komunikasi (TIK) yang telah berpengaruh besar bagi perubahan pada semua bidang, termasuk bidang kesehatan khususnya pada proses rekam medis yang disebut dengan rekam medis elektronik.

Dalam pertemuan KTT Dunia yang diadakan di Jenewa tahun 2003 telah dideklarasikan tentang pemamfaatan potensi teknologi informasi dan komunikasi untuk mendukung Deklarasi Milenium dan diantaranya adalah untuk meningkatkan pelayanan kesehatan. Dalam pertemuan 
WHO ke 58 bulan Mei 2005 telah diadopsi Resolusi WHA58.28 (world Health Assembly) yang menyatakan agar Negaranegara anggota mulai merencanakan pembangunan e-kesehatan yang sesuai untuk masing-masing Negara. Pada tahun yang sama, WHO meluncurkan Observatory Global for Health(OGH), sebuah inisiatif yang didedikasikan untuk studi terhadap evolusi e-kesehatan dan dampaknya pada masing-masing Negara. Model Observatory yaitu menggabungkan peran koordinator WHO regional dengan kantor pusat WHO untuk memantau perkembangan e-Kesehatan di setiap Negara diseluruh dunia melalui survey yang dilakukan dalam dua tahun sekali (Hatta,2014).

Keberhasilan sistem kesehatan nasional sangat ditentukan oleh kinerja masing-masing subsistem termasuk subsistem manejemen kesehatan. Dalam subsistem tersebut, sistem informasi kesehatan menempati posisi yang cukup penting karena berfungsi sebagai tulang punggung untuk mengumpulkan ,mengirimkan, mengolah, menganalisis dan mempublikasikan informasi sekaligus memberikan umpan balik kepada stakeholder di semua tingkat. Ketersediaan data dan informasi yang akurat, terjangkau dan tepat waktu merupakan syarat mutlak pengambilan keputusan manejemen (avidence-based decision making) untuk mendungkung upaya pencapaian tujuan sistem kesehatan nasional (Hatta, 2014).

Menurut UU ITE (2008) pasal 9, Pelaku usaha yang menawarkan produk melalui sistem elektronik harus menyediakan informasi yang lengkap dan benar berkaitan dengan syarat kontrak, produsen, dan produk yang ditawarkan. Pasal 10 (ayat1) setiap pelaku usaha yang menyelenggarakan transaksi elektronik dapat disertifikasi oleh lembaga sertifikasi keandalan (Hatta, 2008).

\section{Perumusan Masalah}

1. Bagaimana perancangan sistem informasi pendaftaran pasien dengan menggunakan Visual Basic 6.0 di RSU
Imelda Pekerja Indonesia PADA periode perancangan April - Juli ?

2. Apakah petugas mampu menggunaan rancangan peneliti dalam melakukan pendaftaran pasien rawat jalan dengan menggunakan Visual Basic 6.0 di RSU Imelda Pekerja Indonesia?

\section{Tujuan Penelitian}

1. Peneliti merancang sistem pendaftaran pasien rawat jalan dengan menggunakan Visual Basic 6.0 di RSU Imelda Pekerja Indonesia Tahun 2018.

2. Untuk mengetahui kemampuan petugas dalam penggunaan Visual Basic 6.0 di RSU Imelda Pekerja Indonesia Tahun 2018.

\section{Manfaat Penelitian}

1. Bagi Peneliti

Diharapkan dalam penelitian ini dapat menerapkan teori dan praktik di lapangan mengenai Rancangan Sistem Pendaftaran Pasien Rawat Jalan Berbasis Visual Basic 6.0 diRSU Imelda Pekerja Indonesia Tahun 2018.

2. Bagi Rumah Sakit

Untuk mempermudah pegawai rumah sakit dalam pendaftaran pasien rawat jalan pada RSU Imelda Pekerja Indonesia dan dengan adanya program yang dibuat dapat membantu cepatnya proses masuknya pasien rawat jalan sehingga pasien mendapatkan pelayanan dan pertolongan yang cepat dan tepat sesuai dengan harapan pasien atau masyarakat.

3. Bagi Instansi Pendidikan

Sebagai bahan bacaan untuk menambah wawasan bagi mahasiswa khususnya sebagai bahan referensi serta sebagai bukti bahwa penulis telah menyelesaikan tugas akhir sebagai syarat dalam menyelesaikan pendidikan Program DIII-Akademi Perekam dan Informasi Kesehatan.

4. Bagi Peneliti Selanjutnya

Diharapkan dapat dikembangkan untuk menjadi penelitian yang mengkaji lebih luas mengenai Rancangan Sistem informasi Pendaftaran Pasien Rawat 
Jalan Berbasis Visual Basic di RSU Imelda Pekerja Indonesia Tahun 2018.

\section{METODE}

\section{Jenis Penelitian}

Jenis penelitian ini adalah perancangan sistem dilakukan dengan menggunakan alur pengembangan sisitem STRADIS (Structure Analysis Desaign And Implementation Of Information System). Penelitian ini dilakukan dengan cara penggunaan tools pengembangan sistem yaitu Data Flow Diagram (DFD).

\section{Tempat Penelitian}

Tempat penelitian di RSU Imelda Pekerja Medan yang beralamat di Jalan Bilal No.52,Kelurahan Pulo Brayan Darat I Kecamatan Medan Timur.

\section{Instrumen Penelitian}

Instrumen yang di lakukan adalah mengamati secara langsung jalannya sistem pengolahan data dan proses kerja pegawai serta melihat format-format data pasien rawat jalan yang digunakan saat ini dengan menggunaan open source milik RSU Imelda Pekerja Indonesia.

\section{Alat Penelitian}

Alat dan bahan yang digunakan dalam penenlitian ini berupa hardware dan software.

1. Perangkat Keras

$$
\text { a. Laptop Acer }
$$

2. Perangkat Lunak
a. Visual Basic 6.0 sebagai bahasa pemograman untuk membuat aplikasi.
b. manajemen database dengan menggunakan Microsoft accses

\section{HASIL}

\section{Perancangan Sistem Informasi}

Perancangan sistem yang dilakukan adalah perubahan input data pasien secara terkomputerisasi, proses pendaftaran pasien rawat jalan terkomputerisasi berbasis Visual Studio 6.0. Adapun perancangan proses ini mencakup pembuatan DFD (Data Flow
Diagram ) level 0, menrancang masukan dan keluaran dari sistem susulan dengan menggunkan visual basic 6.0, merancang kamus data dan merancang user interface susulan.

\section{Perancangan Sistem Basis Data}

Rancangan Basis Data untuk Pengembangan Sistem Informasi Rekam Medis Rawat Jalan untuk pelayanan pasien di RSU Imelda Pekerja Indonesia membutuhkan beberapa tabel yaitu tabel pasien, tabel dokter, tabel rawat diagnosa dan registrasi/resume pasien yang dijabarkan pada uraian berikut:

Tabel 1. Spesifikasi Data Biodata Pasien

\begin{tabular}{|c|c|c|c|}
\hline Field Name & Data Type & Size & Keterangan \\
\hline NoRM & Text & 6 & Nomor Rekam Medik \\
\hline NamaPasien & Text & 25 & Nama Pasien \\
\hline Jenkel & Text & 1 & Jenis Kelamin \\
\hline TempatLahir & Text & 20 & Tempat Lahir Pasien \\
\hline TglLahir & Date/Time & - & Tanggal Lahir \\
\hline Suku & Text & 20 & Suku Pasien \\
\hline Pekerjaan & Text & 30 & Pekerjaan Pasien \\
\hline Agama & Text & 20 & Agama Pasien \\
\hline Alamat & Text & 50 & Alamat Pasien \\
\hline
\end{tabular}

Tabel 2. Spesifikasi Data Rawat Jalan

\begin{tabular}{cccc}
\hline Field Name & Data Type Size & Keterangan \\
\hline NoRM & Text & 6 & Nomor Rekam Medik \\
\hline TglMsk & Date/Time & - & Tanggal Masuk Pasien \\
\hline Catatan & Text & 15 & Catatan Dokter \\
\hline Diagnosa & Text & 15 & Hasil Diagnosa \\
\hline Keterangan & Text & 25 & Keterangan Tambahan \\
\hline
\end{tabular}

Tabel 3. Spesifikasi Data Dokter

\begin{tabular}{ccc}
\hline Field Name & $\begin{array}{c}\text { Data } \\
\text { Type }\end{array}$ & Keterangan \\
\hline Kode dokter & Kode & Kode doketer yang ada di RS \\
\hline Nama dokter & Text & Nama doketer yang ada di RS \\
\hline Spesilisasi & Text & Spesialis Dokter \\
\hline
\end{tabular}

\section{Rancangan Logika Program}

Untuk mendukung proses pendaftaran pasien rawat jalan padadi Rumah Sakit Imelda Pekerja Indonesia dirancang sebuah program dengan menggunakan bahasa pemrograman Visual Basic.6.0 Dalam rancangan logikan ini menggunakan $D F D$ (data flow diagram). 


\section{Perancangan DFD level 0}

Data flow diagramlevel 0 adalah diagram yang menggambarkan proses dari data flow diagram. Diagram nol memberikan pandangan secara menyeluruh mengenai sistem yang ditangani,

Gambar 1. Data Flow Diagram Level 0

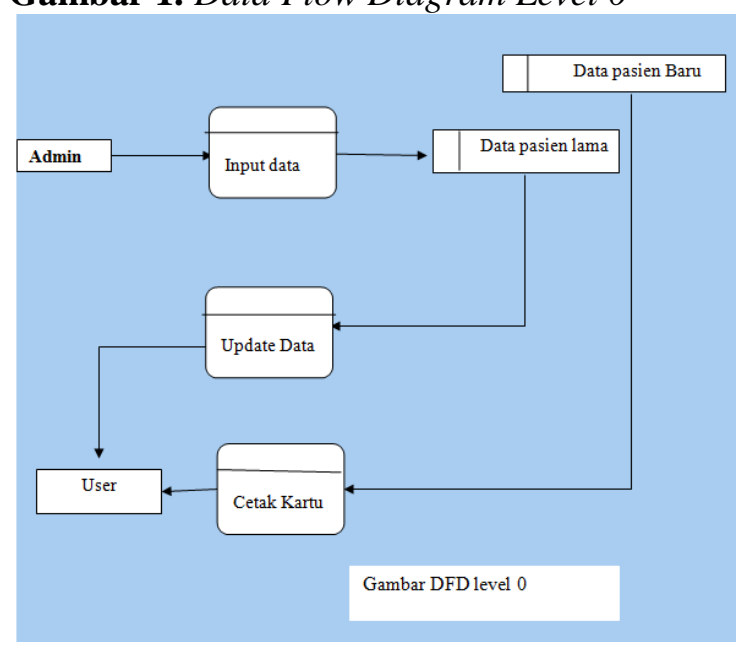

Keterangan pada DFD perancangan sistem informasi pendaftaran

\section{Entitas}

a. Admin adalah petugas pengelolah data pasien kedalam sistem informasi pendaftaran pasien.

b. User adalah pelanggan atau pasien rawat jalan di rumah sakit Imelda pekerja Indonesia.

2. Proses

Input Data adalah proses untuk menginput data pasien rawat jalan ke dalam sistem.

a. Update Data adalah proses untuk melakukan pembaharuan data pasien yang ada dalam sistem.

b. Cetak kartu adalah proses untuk melakukan pencetakan kartu bagi menunjukkan tentang fungsi-fungsi utama atau proses yang ada, aliran data dan external entity. Data Flow Diagram Level 0 dapat dilihat seperti pada Gambar dibawah ini:

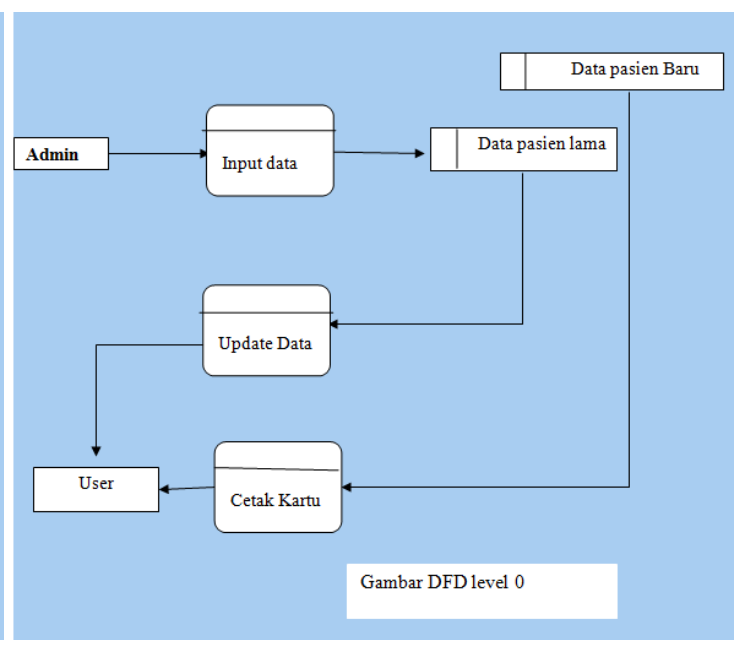

pasien baru dari urutan akhir nomor rekam medis.

c. No. antrian adalah proses untuk melakukan cetak nomor antrian saat pasien melakukan pendaftaran.

\section{Data Storage}

a. Data pasien lama adalah tempat untuk menyimpan data pasien lama dari admin.

$b$. Data pasien baru adalah tempat untuk menyimpan data pasien baru dari admin.

\section{FlowChart}

Tahap desain logika merupakan tahap awal pemrograman. Urutan langkahlangkah serta logika dari suatu program computer yang telah dirancang. 
2. FlowChart Menu Utama

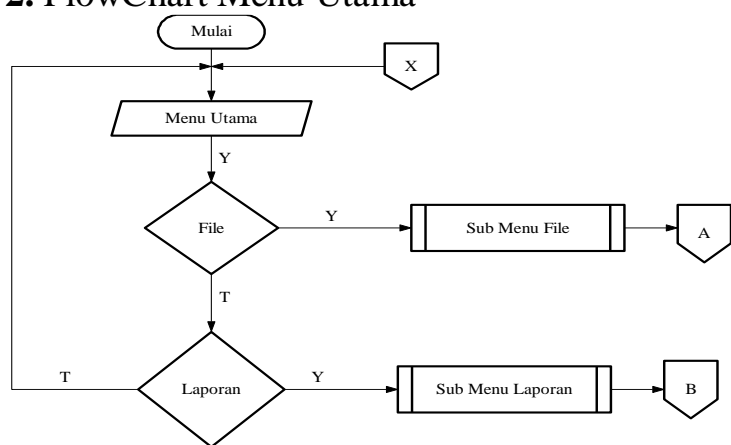

Keterangan :

Pada Flowchart menu utama ada beberapa pilihan untuk memasuki sub menu diantaranya adalah menu file (A), menu file (A) masihmenyimpan beberapa file didalamnya yang tersimpan dalam database

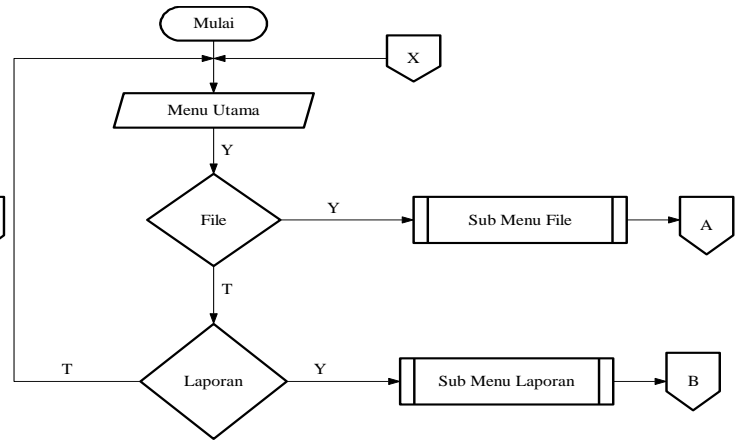

dan menu file (B) juga masih menyimpan beberapa data di dalamnya yang memuat tentang laporan-laporan data pasien yang memungkinkan akan menjadi sebuah sistem informasi yang penting.

\section{PEMBAHASAN}

\section{Hasil Rancangan}

1. Rancangan Tampilan Menu Utama

Gambar 3. Rancangan Tampilan Menu Utama

\section{PENDAFTARAN PASIEN RAWAT JALAN}

\section{BERBASIS VISUAL BASIC 6.0}


2. Tampilan Entry Data Pasien

Gambar 4. Tampilan Entry Data Pasien

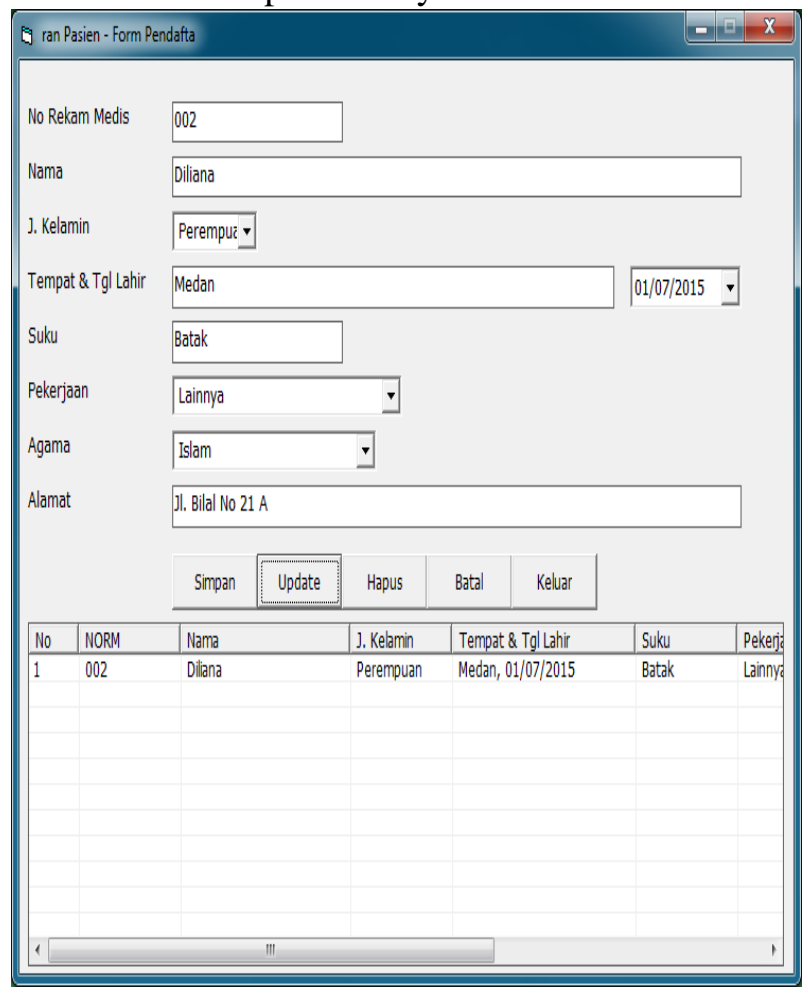

3. Tampilan Entry Data Dokter

Gambar 5. Tampilan Entry Data Dokter

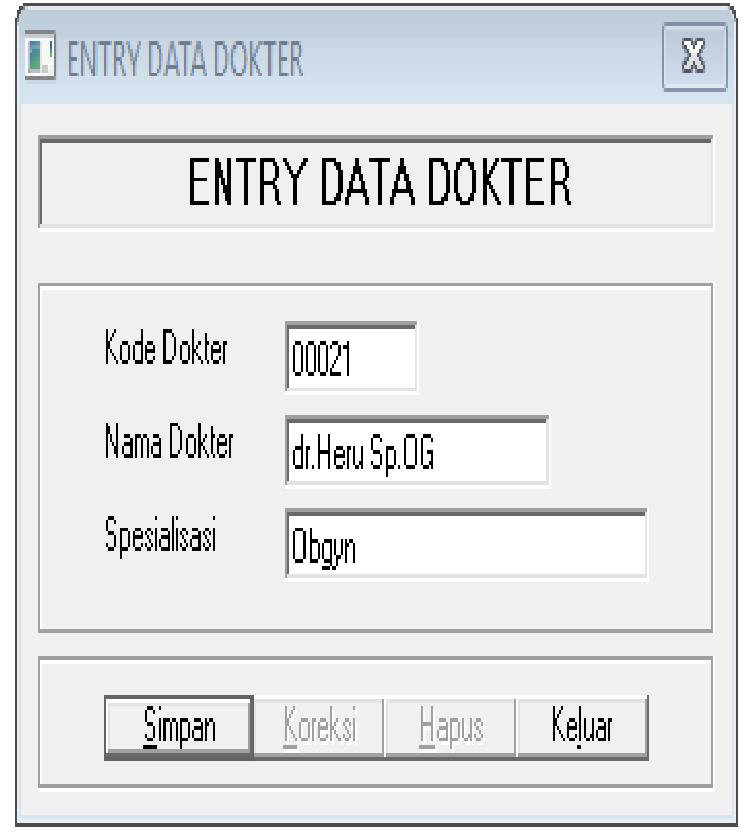




\section{Tampilan Rawat Jalan}

Gambar 6. Tampilan Rawat Jalan

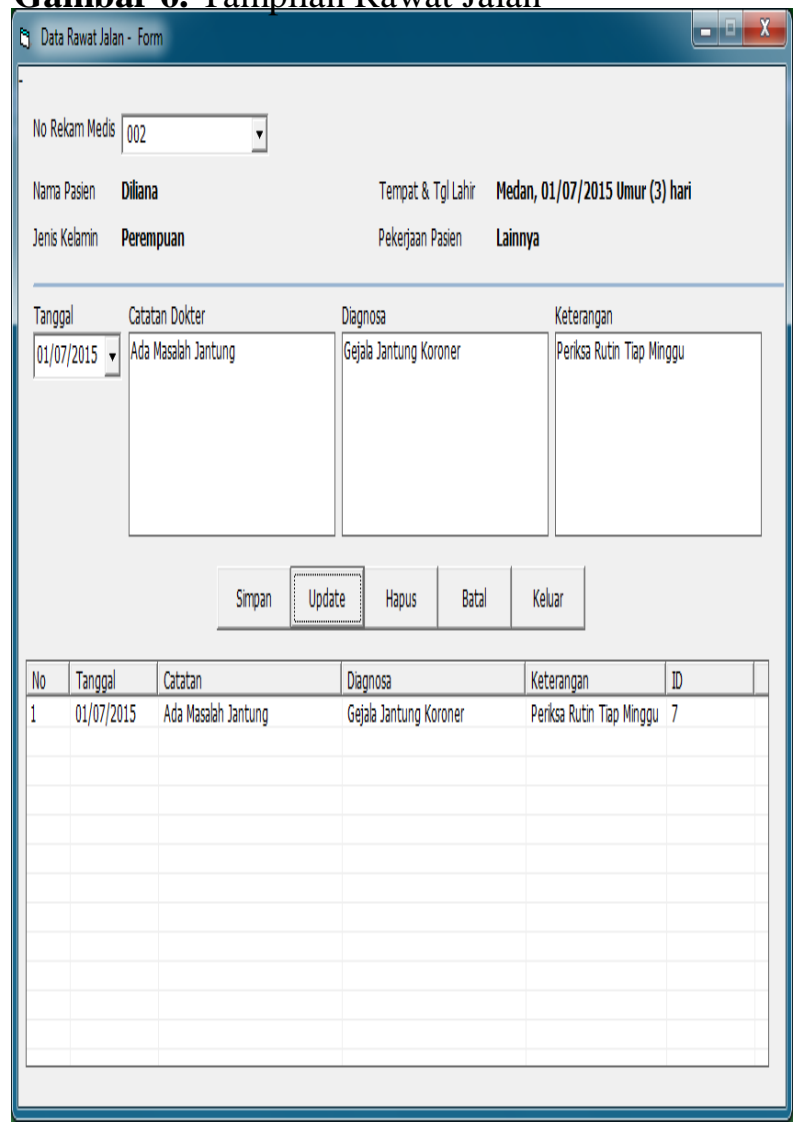

5. Rancangan Tampilan Menu Laporan

Gambar 7. Rancangan Tampilan Menu Laporan

I B. B.|W:LA

Fin: LaOWin Window

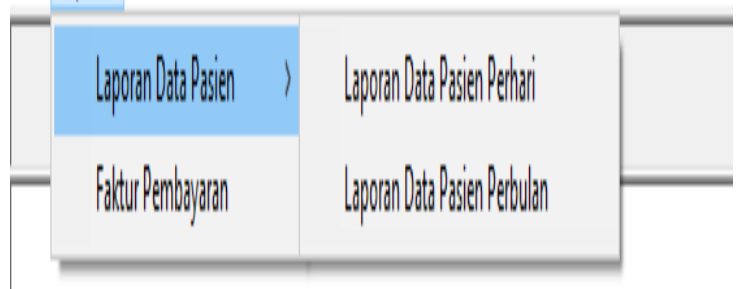

\section{KESIMPULAN}

1. Aplikasi sistem informasi pendaftaran pasien rawat jalan berbasis visual basic 6.0 yang dirancang dapat mengelola data pasien (input, edit, hapus), data Transaksi perawatan (input, edit, hapus) dan laporan (data pasien, data rawat jalan),Data Dokter.
2. Bahasa Pemrograman Visual Basic merupakan bahasa pemrograman yang handal untuk merancang aplikasi berbasis database dan Microsoft Access merupakan salah satu aplikasi pengolahan database yang mudah dipelajari.

3. Aplikasi sistem informasi pendaftaran pasien rawat jalan yang dirancang oleh 
peneliti mampu dijalankan oleh petugas pendaftaran walaupun masih ada kekurangan dalam rancangan.

\section{SARAN}

1. Untuk meningkatkan sistem Informasi pendaftran pasien rawat jalan berbasis visual basic 6.0 dengan menu-menu dan fiture yang lebih lengkap.

2. Agar dapat meningkatkan pengetahuan bahasa pemograman dan memantapkan pengolahan Database dengan menggunakan Microsoft Accsess.

3. Agar mengembangkan rancangan menjadi lebih lengkap dan terstruktur.

\section{DAFTAR PUSTAKA}

Agusli, R, Sakuroh, L, Novryandi. (2016). Perancangan Sistem Informasi Kesehatan (Puskesmas Keliling) Berbasis Web. Jurnal Sisfotek Global. ISSN : $2088-1762-2016$.

Campbell,et.al. (2006). The impact of Health care : Coping with two unavoidable hybrids and a potentially infite workload. Birmingham : UK.

Departemen Kesehatan Republik Indonesia. (2008). Peraturan Mentri Kesehatan RI NO. 262 pasal II tahun 2008 tentang Jenis Dan isi Rekam Medis. Jakarta: Departement Kesehatan RI .

Fawadry. (2007). Electronic record in maternity care: coping with two Unavoidable hybrids and a potentially infinite workload. Birmingham: UK.

Gemala, R Hatta. (2014). Pedoman Manajemen Informasi Kesehatan disarana pelayanan kesehatan. Jakarta: UI-Press.

Hendry. (2008). The Challege of developing an electronic health Record for Use by
Mobile Community Based Health Practioners. Cristhurch: New Zealand. Heinzer. M. (2010). Essential Element of Nursing Notes and The Transition to electronic Health record. JHMFALL,Vol 24, No.4:53-59.

Imam, Mutiara, Rifki. (2013). Pengembangan Web Service Transformasi Data Kesehatan Berbasis Open EHR Menjadi Standar Health Level Seven (HL7) (OpenEHR to HL7). Depok: Gunadarma.

Jogiyanto, Hartono. (2007). Pengenalan Komputer : Dasar Ilmu Komputer, Pemrograman, Sistem Informasi dan Intelegensi Buatan. Yogyakarta: Andi.

Kristanto, Andri. (2003). Perancangan Sistem Informasi dan Aplikasinya. Yogyakarta: Gava Media.

Kursini. (2008). Konsep dan Aplikasi Sistem Pendukung Keputusan. Yogyakarta: Andi.

Marthiawat. N, Mulyono, H. (2017). Analisis Dan Perancangan Sistem Electronic Medical Record (Emr) Berbasis Web Pada Klinik Mata Kambang. Jurnal Manajemen Informasi. DOI: $10.11591-2017$.

Putra. K, Rohmadi, Mulyono. S. (2013). Perancangan Sistem Informasi Pendaftaran Pasien Rawat Jalan Di Klinik Dr. Sri Widatik Sukoharjo Berbasis Web. Jurnal Rekam Medis. ISSN 1979-9551-2013.

Sutanta, Edhy. (2011). Basis Data Dalam Tinjauan Konseptual. Yogyakarta: Andi.

Thede, L. (2008). Electronic Personal Health Reacord: Nursing's Role. OJIN: The Onilne Journal of Issues in Nursing Vol.14 No.1.

Wahyudi, Bambang. (2008). Konsep Sistem Informasi: Dari Bit Sampai Ke Database. Yogyakarta: Andi Offset.

Widiartono. (2018). Sistem Informasi Manajement. 2014.diakses 2 Juli 2018. http://books.google.co.id 